\title{
(Note】
}

\section{Radical Copolymerization of Ferulic Acid Derivatives with Ethylenic Monomers}

\author{
Hong Sun*1, Yoon Deuk Young*1, Shinji Kanehashi*1, Kousuke Tsuchiya*1, \\ Kenji Ogino*1,*, and Jae-Ho Sim*2 \\ ${ }^{* 1}$ Graduate School of Bio-Applications and Systems Engineering, Tokyo University of Agriculture and Technology, \\ 2-24-16 Nakacho, Koganei-shi, Tokyo 184-8588, Japan \\ ${ }^{* 2}$ Department of Advanced Material and Chemical Engineering, Faculty of Engineering, Halla University, \\ 28 Halladae-gil, Wonju, Gangwon 220-712, Korea
}

\begin{abstract}
Bio-based ferulic acid (FA), (E)-3-(4-hydroxy-3-methoxyphenyl)prop-2-enoic acid was converted to 1,2-disubstituted ethylenic monomer (FA1) via methyl esterification followed by silylation with tertbutyldimethylsilyl chloride. Radical copolymerization of FAl with styrene (St), methyl methacrylate (MMA), and 4-acetoxy-3-methoxystyrene (FA2) prepared from FA were carried out using azobisisobutyronitrile as an initiator at $80^{\circ} \mathrm{C}$. It is found that FA1 was copolymerized with St and FA2, but not with MMA. The formation of copolymers was confirmed by ${ }^{1} \mathrm{H}$ - and ${ }^{13} \mathrm{C}-\mathrm{NMR}$ analyses. The reactivity ratios of FA1 and St estimated by the Fineman-Ross method are $r_{\mathrm{FAl}}=0.12$ and $r_{\mathrm{st}}=2.46$. In the case of the copolymerization of FA1 with FA2, the reactivity ratios, $r_{\mathrm{FA} 1}=0.13$ and $r_{\mathrm{FA} 2}=2.66$ were determined.
\end{abstract}

(Received 26 December, 2015; Accepted 29 January, 2016)

\section{Introduction}

Ferulic acid (FA), (E)-3-(4-hydroxy-3-methoxyphenyl)prop-2-enoic acid is one of the bio-based sustainable chemicals, found in commelinid plants such as rice, wheat, oats, and pineapple. FA is the building block of lignocelluloses, and lignin. A variety of alkaline, acid, and enzymatic methods for the extraction and isolation of FA have been reported in the literature.[1-6] As recently reviewed, FA has been widely applied in biomedical, pharmaceutical, food, cosmetic and other industries.[7] It is also of interest to prepare polymeric materials using bio-based FA as a starting material from the view point of sustainable development.

FA is a multi-functional chemical possessing hydroxyl, and carboxy groups. Using these functional groups, PET mimics polyester [8], poly(esteralkenamer)s via an acyclic diene metathesis reaction [9], poly(ester-urethane)s [10], aliphatic-aromatic copolyesters [11] have been prepared. Since FA has a double bond conjugated with carbonyl and aryl groups, it is also regarded as one of the 1,2- disubstituted ethylenes. In the case of vinyl polymerization, hydroxyl and carboxy groups are not consumed in the polymerization reaction, and remain in the side chains leading to the other type of functional polymers. Radical polymerization of FA and its derivative or copolymerization with comonomers is an easy way to achieve bio-based polymers. It is generally believed that 1,2 disubstituted ethylenic monomers are not radically homopolymerized due to the steric hindrance except for $N$-alkyl or phenyl maleimides [12], and fumarates with bulky ester alkyl groups [13]. Meanwhile, 1,2disubstituted monomers such as cinnamate and maleic anhydride can be copolymerized with conventional monomers such as styrene, and methyl methacrylate. FA is considered as an analogue of cinnamic acid, where phenolic hydroxy and methoxy groups are additional functional groups to cinnamic acid. In this paper, copolymerization behaviors of FA modified monomer with styrene, methyl methacrylate and styrene derivative resulting from the decarbonation of FA [14] are investigated. In order to design novel renewable polymeric materials, it is of

\# corresponding author : E-mail : kogino@cc.tuat.ac.jp ; 
importance to understand the basic characteristics of FA derivatives in a radical polymerization.

\section{Experimental Section}

\subsection{Materials}

All chemicals were brought from Wako Chemical (Japan), and were used as received unless otherwise noted.

\subsection{Synthesis}

trans-4-Hydroxy-3-methoxy cinnamic acid methyl ester

To a 200-mL two-necked round bottom flask equipped with a condenser, and a magnetic stirrer were added FA (3.0 g, $0.015 \mathrm{~mol})$ and methanol $(80 \mathrm{~mL})$. After the addition of ten drops of sulfuric acid, the solution was refluxed for $24 \mathrm{~h}$. After the evaporation of methanol, the residual yellow oil was dissolved in ethyl acetate followed by washed with sodium bicarbonate solution and brine. After drying with magnesium sulfate, the solvent was removed, and the resulting yellow oil was dried in vacuo $(3.13 \mathrm{~g}$, 99\%).

trans-4-tert-Butyldimethlysiloxy-3-methoxy cinnamic acid methyl ester (FA1)

To a 100-mL two-necked round bottom flask equipped with a magnetic stirrer and a dropping funnel was added trans-4-hydroxy-3-methoxy cinnamic acid methyl ester (3.13g, 0.015mol), imidazole $(11.3 \mathrm{~g}, 0.045 \mathrm{~mol})$, and $20 \mathrm{~mL}$ of dehydrated $\mathrm{N}, \mathrm{N}$ dimethylformamide. tert-Butyldimethylsilyl chloride (7.56 g, $0.03 \mathrm{~mol})$ was added dropwise at room temperature, and the reaction mixture was stirred for $4 \mathrm{~h}$. After the addition of $50 \mathrm{~mL}$ of water, the resulting solution was extracted with ethyl acetate $(20 \mathrm{~mL} \times 3)$. The organic layer was washed with brine, and the solvents were evaporated. The crude product was purified with column chromatography (silica, hexane / ethyl acetate $=5$ / 1). Recrystallization from ethanol afforded a colorless crystal $\left(3.78 \mathrm{~g}, 81 \%\right.$, m.p. : $\left.65^{\circ} \mathrm{C}\right)$ [15]. ${ }^{1} \mathrm{H}$ NMR (300 MHz, $\left.\mathrm{CDCl}_{3}\right), \delta$ (ppm) from TMS: 7.60 (d, 1H, $J=16.2 \mathrm{~Hz}), 7.00(\mathrm{~m}, 2 \mathrm{H}), 6.84$ (d, 1H, $J=$ $8.7 \mathrm{~Hz}$ ), 6.28 (d, 1H, J=16.2 Hz), 3.80 (s, 3H), 3.76 (s, 3H), 0.97 (s, 9H), 0.15 (s, 3H). ${ }^{13} \mathrm{C}$ NMR $\left(75 \mathrm{MHz}, \mathrm{CDCl}_{3}\right) \delta$ (ppm) from TMS : 167.57, 151.07, 147.42, 144.86, 128.14, 122.12, 120.97, 115.37, 110.71, 56.27, 51.46, 25.57, 18.37, 4.70 .

\section{4-Acetoxy-3-methoxystyrene (FA2)}

To a 200-mL two-necked round bottom flask equipped with a magnetic stirrer and a condenser was added FA (5.0 g, 0.026 mol), triethylamine (2.45 mL, $0.026 \mathrm{~mol}$ ), and $100 \mathrm{~mL}$ of toluene. The resulting dispersion was refluxed for $7 \mathrm{~h}$. After confirming decarbonation, acetic anhydride $(3 \mathrm{~mL}$, $0.027 \mathrm{~mol}$ ) and trimethylamine ( $3 \mathrm{~mL}, 0.029 \mathrm{~mol}$ ) were added. After stirring for $5 \mathrm{~h}$, the reaction mixture was cooled to room temperature, washed with sodium bicarbonate solution and brine three times, successively. The crude product was purified with column chromatography (silica, hexane / ethyl acetate $=3 / 1$ ). Evaporation of the solvents afforded reddish oil (4.42 g, 81\%). ${ }^{1} \mathrm{H}$ NMR (300 $\left.\mathrm{MHz}, \mathrm{CDCl}_{3}\right), \delta$ (ppm) from TMS : 6.98 (m, 3H), $5.66(\mathrm{dd}, 1 \mathrm{H}, J=15.5 \mathrm{~Hz}$, $9.5 \mathrm{~Hz}$ ), 5.67 (dd, 1H, $J=15.5 \mathrm{~Hz}, 3.0 \mathrm{~Hz}$ ), 5.23 (dd, 1H, $J=$ $9.5 \mathrm{~Hz}, 3 \mathrm{~Hz}$ ), 3.81 (s, 3H), 2.28 (s, 3H).

\subsection{General procedure of copolymerization of FA1}

To a glass ampule equipped with a magnetic stirrer, and a three-way stop-cock were charged with the mixture of FA1 and another monomer (total amount; $6.9 \mathrm{mmol}$ ), and AIBN (2 mol\%). After four freeze-pump-thaw cycles, the reaction tube was heated at $80^{\circ} \mathrm{C}$ under nitrogen atmosphere. The reaction mixture was poured into methanol to precipitate the product. Reprecipitation procedure was carried out twice, and the product was dried overnight in vacuo.

\subsection{Characterization}

${ }^{1} \mathrm{H}$ - and ${ }^{13} \mathrm{C}-\mathrm{NMR}$ spectra were obtained on a JEOL ALPHA300 instrument at 300 and $75 \mathrm{MHz}$, respectively. Deuterated chloroform $\left(\mathrm{CDCl}_{3}\right)$ was used as a solvent with tetramethylsilane (TMS) as an internal standard. Molecular weight and its distribution were estimated with gel permeation chromatography equipped with JASCO 880-PU pump, a column packed with styrene-divinylbenzene gel beads [16], and a JASCO UV-970 detector. Chloroform was used as an eluent, and the molecular weitght was calibrated using polystyrene standards.

\section{Results and discussion}

\subsection{Monomer synthesis}

As shown in Introduction, FA possesses phenolic hydroxyl group. In general radical polymerizations, hydrogen abstraction reaction of a propagating radical from hydroxyl group in a phenol derivative efficiently occurs, and the resulting radical is subject to the combination reaction with the other radical species (degradative chain transfer).[17] Consequently phenol acts as an inhibitor in radical polymerizations. 


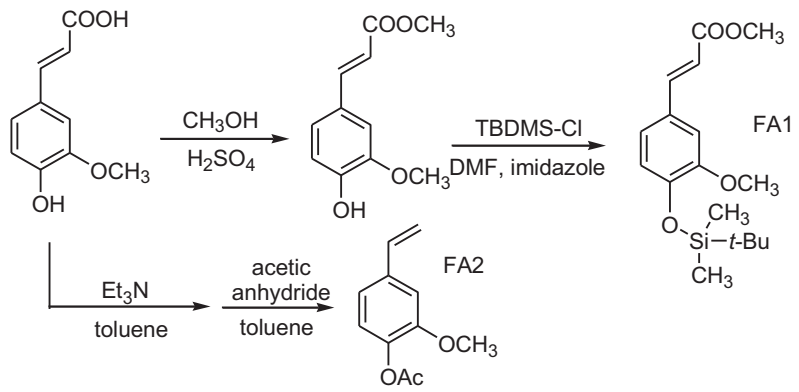

Scheme 1 Synthesis of monomers from ferulic acid (FA)

Preliminary study revealed that solubility of FA derivative where hydroxyl group is protected by acetyl group is still not sufficient to be copolymerized with styrene in a bulk or a high concentrated solution. In the molecular design in this study, hydroxy group in FA is protected by tert-butyldimethylsilyl group, and carboxy group is converted to methyl ester in order to improve the solubility.

Designed monomer (FA1) was synthesized via two step processes, i.e. methyl esterification and subsequent silylation as shown in Scheme 1. Both reactions proceeded in over $80 \%$ yields, and in high purities. In ${ }^{1} \mathrm{H}-\mathrm{NMR}$ spectrum of resulting FA1, two types of methoxy signals appear at 3.76 and $3.80 \mathrm{ppm}$. Two kinds of protons in the protecting silyl group show singlet signals at 0.15 and $0.97 \mathrm{ppm}$. All other signals can be assigned to confirm that the desired molecule was obtained. As expected, FA1 shows high solubility in conventional solvents such as methanol, acetone, THF, toluene, chloroform, and hexane.

In order to increase the bio-based content of the FA1 based copolymers 4-acetoxy-3- methoxystyrene (FA2) was prepared from FA via the thermal decarbonation followed by the acetylation. In ${ }^{1} \mathrm{H}-\mathrm{NMR}$ spectrum of FA2, all the expected signals appeared confirming the successful synthesis of FA2 [14].

\subsection{Copolymerization of FA1 with styrene}

Due to the improved solubility of FA1, it is possible to carry out a bulk polymerization or a solution polymerization in concentrated conditions. At first FA1 was copolymerized with conventional styrene. Copolymerizations were conducted varying FA1 content from 10 to $90 \mathrm{~mol} \%$ in feed. Runs $1-3$, homogeneous liquids for the monomer mixture were obtained, and were copolymerized in bulk. In runs 4 , and $5,0.3 \mathrm{~mL}$ of toluene was added to the monomer mixture to afford the homogeneous mixture. In order to estimate the reactivity ratio of each monomer, the conditions were established so that polymerization yield was less than $5 \%$. In run 5 , methanol insoluble product was negligible. Figure 1 shows ${ }^{1} \mathrm{H}-\mathrm{NMR}$ spectrum of the product (run 3). Two signals originated from silyl group appeare at 0.03 and $0.93 \mathrm{ppm}$ confirming the incorporation of FA1 into the product. With the comparison of intensities of these signals to aromatic signal, the chemical compositions were determined as shown in Table 1. The contents of FA1 in polymers are lower than those in feed suggesting the lower monomeric reactivity than styrene due to the steric hindrance. The details of copolymerization analyses are discussed below. Propagation reactions involving FA1 radical are also retarded judging from the decrease of yield with the increase of FA1 contents.

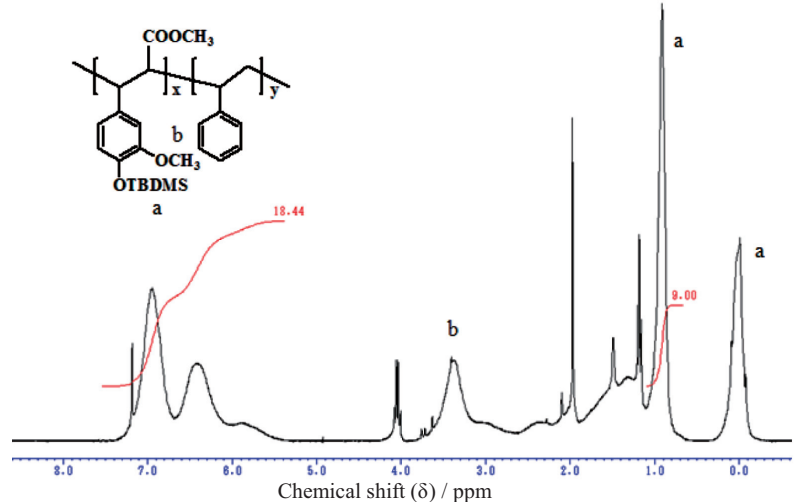

Fig. $1{ }^{1} \mathrm{H}-\mathrm{NMR}$ spectrum of copolymer (run 3) in $\mathrm{CDCl}_{3}$ at $300 \mathrm{MHz}$

Table 1 Copolymerization of FA1 with styrene

\begin{tabular}{cccccc}
\hline \multirow{2}{*}{ Run } & \multicolumn{2}{c}{ content of FA1 (mol\%) } & Yield (\%) & $M_{\mathrm{n}}{ }^{* 2} / 10^{3}$ & PDI $^{{ }^{* 2}}$ \\
\cline { 2 - 4 } & in feed & in polymer & & \\
\hline 1 & 10.1 & 4.2 & 4.40 & 6.7 & 1.81 \\
2 & 29.7 & 13.4 & 2.10 & 9.4 & 1.84 \\
3 & 49.7 & 24.5 & 0.84 & 9.1 & 1.74 \\
$4^{* 3}$ & 69.3 & 37.7 & 0.05 & 7.5 & 1.56 \\
$5^{* 3}$ & 89.3 & - & - & - & - \\
\hline
\end{tabular}

Total amount of monomers ; $6.9 \mathrm{mmol}, \mathrm{AIBN} ; 2 \mathrm{~mol} \%$. Polymerizations were carried out at $80^{\circ} \mathrm{C}$ for $5 \mathrm{~min}$.

${ }^{* 1}$ determined by ${ }^{1} \mathrm{H}-\mathrm{NMR}$ data

*2 determined by GPC calibrated with polystyrene standards

*3 containing toluene $(0.3 \mathrm{~mL})$ as an additional solvent 
${ }^{13} \mathrm{C}$-NMR analyses on the copolymers were also carried out, which have been widely used to investigate the microstructure such as monomer sequence, tacticity, and regioregularity. Figures 2 and 3 show ${ }^{13} \mathrm{C}$-NMR spectra of copolymers. As shown in Figure 2, characteristic signals from silyl, methoxy, carbonyl groups are observed confirming the formation of the copolymer (run 3). In Figure 3, expanded signals for carbonyl, and ipso carbons (from styrene, and FAl connected to the main chain) are presented for the copolymers in runs 1 (upper), and 3 (lower).

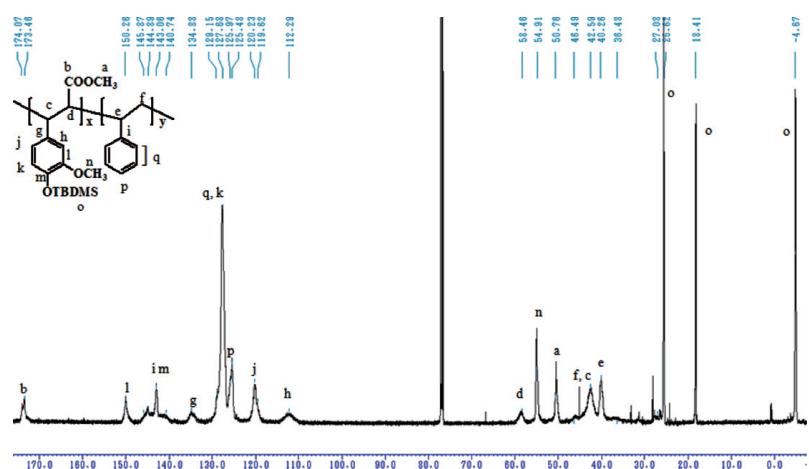

Fig. $2{ }^{13} \mathrm{C}-\mathrm{NMR}$ spectrum of copolymer (run 3) in $\mathrm{CDCl}_{3}$ at $75 \mathrm{MHz}$

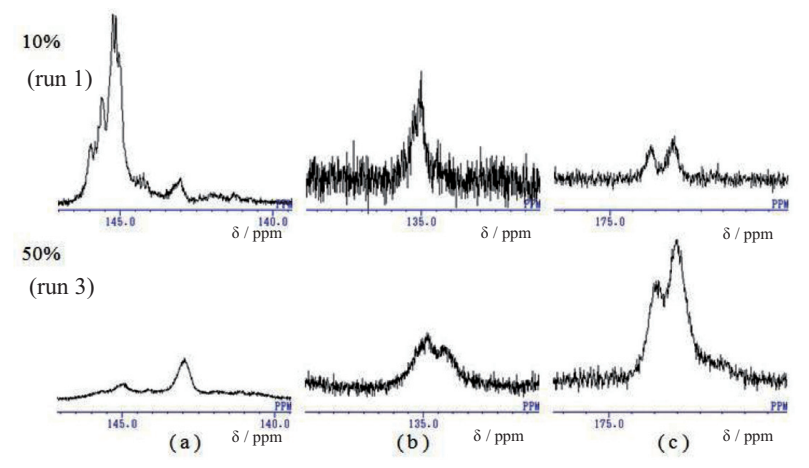

Fig. $3{ }^{13}$ C-NMR spectra of copolymers (run 1; upper and run 3 ; lower) a) i and $\mathbf{m}$ ipso carbons in styrene and FA1 moieties, respectively (assignment; shown in the inserted figure in Figure 2), b) g ipso carbon in FA1 moiety, which is connected to the main chain), and c) $\mathbf{b}$ carbonyl carbon.

Since the styrene content of the copolymer (run 1) is high, the signal i (around $145 \mathrm{ppm}$ ) can be assigned to ipso carbon on styrene sequence taking the assignments of polystyrene into consideration (signal splitting is due to triad and pentad tacticity [18]). With the increase of FAl content, the number of styrene sequence decreases, and broadening occurs in the copolymer with high FA1 content (run 3). Around $135 \mathrm{ppm}$, a relatively sharp signal appears for the copolymer (run 1). This signal is assigned to ipso carbon in FA1 moiety, which is connected to the main chain. In the copolymer (run 1), it is reasonable that this FA1 moiety is isolated in the long styrene sequence, taking low FAl content into consideration. With the increase of FAl content, a new signal appears at the higher magnetic field. It is speculated that this signal is caused by shortening of styrene sequence in the copolymer (run 3). Carbonyl carbon shows apparent signal splitting. As discussed above, FA1 unit is considered to be isolated in the copolymer (run 1). Therefore this splitting is not resulted from the monomer sequence. Assuming that the attack of styryl radical to FA1 at $\alpha$-carbon of carbonyl group, and propagating radical is predominantly located at $\alpha$ carbon of aromatic ring in FA1 [19], difference of cotacticity resulted in signal splitting. Further investigation is necessary to elucidate the microstructure of copolymers.

\subsection{Copolymerization of FA1 with FA2}

Styrene analogue, 4-acetoxy-3-methoxystyrene (FA2) was prepared from FA. The utilization of FA2 instead of styrene, makes it possible to increase the bio-based content of the products. Copolymerizations of FA1 with FA2 were investigated in a similar way where styrene is used as a comonomer. ${ }^{1} \mathrm{H}-\mathrm{NMR}$ of the product (run 8) is shown in Figure 4. Compared with the case of styrene, signals for aromatic protons are shifted to higher-magnetic field, and the resonance for acetyl proton appears around at $2.3 \mathrm{ppm}$ in addition to that of silyl group. These facts strongly suggest that both monomers are incorporated in the product. At higher content of FA1, no product insoluble in methanol was obtained. Similar tendency about dependence of monomer content on the chemical composition, and the yield is observed. Higher yield and molecular weight of copolymer were observed in the copolymerization of FA1 with FA2, suggesting the higher reactivity of

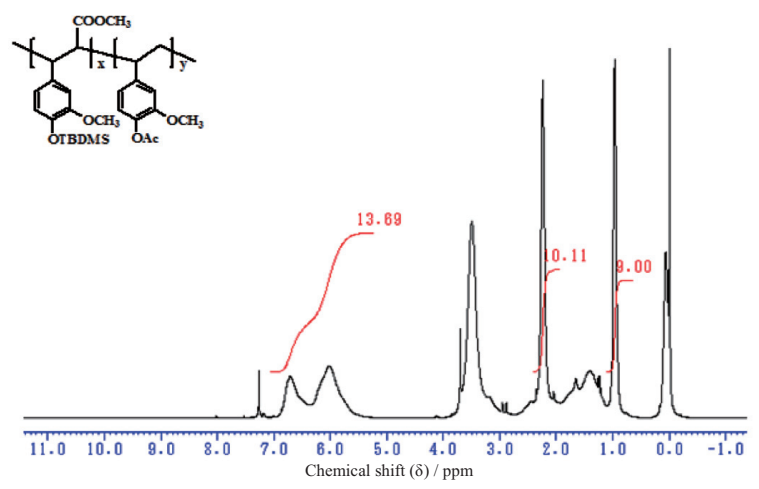

Fig. $4{ }^{1} \mathrm{H}-\mathrm{NMR}$ spectrum of copolymer (run 8) in $\mathrm{CDCl}_{3}$ at $300 \mathrm{MHz}$ 
Table 2 Copolymerization of FA1 with FA2

\begin{tabular}{cccccc}
\hline \multirow{2}{*}{ Run } & \multicolumn{2}{c}{ content of FA1 $\left(\mathrm{mol}^{\circ}\right)$} & Yield $(\%)$ & $M_{\mathrm{n}}{ }^{* 2} / 10^{3}$ & PDI $^{* 2}$ \\
\cline { 2 - 4 } & in feed & in polymer & & \\
\hline $6^{* 3}$ & 9.9 & 3.9 & 10.8 & 53.4 & 2.32 \\
$7^{* 3}$ & 30.2 & 12.9 & 6.0 & 43.4 & 2.31 \\
$8^{* 3}$ & 48.8 & 22.9 & 1.5 & 20.0 & 1.49 \\
$9^{* 3}$ & 69.0 & - & - & - & - \\
$10^{* 3}$ & 89.8 & - & - & - & - \\
\hline
\end{tabular}

Total amount of monomers ; $6.9 \mathrm{mmol}$, AIBN ; 2mol\%. Polymerizations were carried out at $80^{\circ} \mathrm{C}$ for $5 \mathrm{~min}$.

${ }^{* 1}$ determined by ${ }^{1} \mathrm{H}-\mathrm{NMR}$ data

*2 determined by GPC calibrated with polystyrene standards

${ }^{* 3}$ containing toluene $(0.3 \mathrm{~mL})$ as an additional solvent

FA2 than styrene.

\subsection{Copolymerization analyses}

From the data about chemical compositions, monomer reactivity ratios $\left(r_{1}\right.$, and $r_{2}$ for $\mathrm{M}_{1} ; \mathrm{FA} 1$, and $\mathrm{M}_{2}$; styrene or FA2) were estimated using a straight line intersection method and the Fineman-Ross method. The intersection method afforded the reactivety ratios, $r_{1}=0.13 \pm 0.02$, and $r_{2}=2.47 \pm 0.05$ for styrene, and $r_{1}=0.13 \pm 0.01$, and $r_{2}=2.63 \pm 0.02$ for FA2. Figure 5 shows the Fineman-Ross plots for two sets of monomers. Highly reliable straight lines were obtained. Monomer reactivity ratios are estimated as $r_{1}=0.12$, and $r_{2}=2.46$ for styrene, and $r_{1}=0.13$, and $r_{2}=$ 2.66 for FA2, and these values are consistent with those obtained by the intersection method. Reactivity ratios of alkyl cinnamate (M1) with styrene (M2) were reported as $r_{1}=0.10$, and $r_{2}=2.03$ for methyl cinnamate,

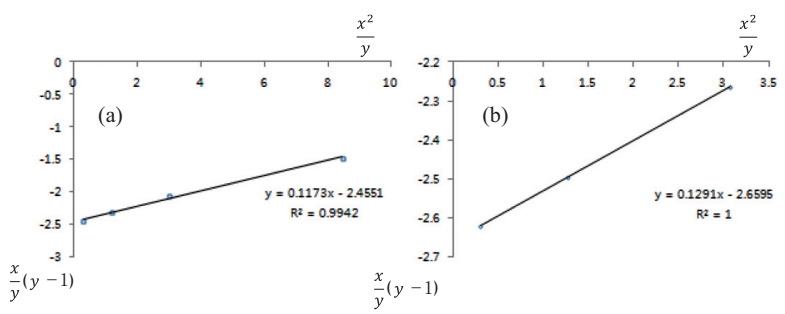

Fig. 5 Fineman-Ross plots for (a) styrene and (b) FA2 as a monomer 2. $x=\left[\mathrm{M}_{1}\right] /\left[\mathrm{M}_{2}\right], y=\mathrm{d}\left[\mathrm{M}_{1}\right] / \mathrm{d}\left[\mathrm{M}_{2}\right]$ and 0.10 and 1.50 for ethyl cinnamate.[20] Similar to presented data, higher self-propagation rate of styrene was suggested.

\subsection{Copolymerization of FA 1 with methyl methacrylate (MMA)}

Copolymerization of FA1 with the other conventional ethylenic monomer, methyl methacrylate (MMA) was also investigated. Similar to styrene, copolymerization of FA1 with MMA in 5 different feed ratio was carried out. Table 3 shows the polymerization conditions and results. Contrary to styrene, it is found that FAl cannot be copolymerized essentially with MMA. At the low content of FA1, PMMA homopolymer was obtained. However, no polymer was produced at the high content of FA1. It is noteworthy that molecular weights of products are almost independent of the content of FA1. Therefore, the propagating end involving MMA cannot react with FA1 probably due to the fact that MMA is 1,1disubstituted monomer, and steric hindrance between propagating radical and FA1 monomer is severe.

\section{Conclusions}

Bio-based FA was converted to 1,2-disubstituted ethylenic monomer via methyl esterification followed

Table 3 Copolymerization of FA1 with MMA

\begin{tabular}{cccccc}
\hline \multirow{2}{*}{ Run } & \multicolumn{2}{c}{ content of FA1 $(\mathrm{mol} \%)$} & Yield $(\%)$ & $M_{\mathrm{n}}{ }^{* 2} / 10^{3}$ & PDI $^{* 2}$ \\
\cline { 2 - 5 } & in feed & in polymer & & \\
\hline 11 & 9.8 & 0 & 4.8 & 11.3 & 2.89 \\
12 & 30.1 & 0 & 5.4 & 11.9 & 2.31 \\
$13^{* 3}$ & 50.2 & $<0.1$ & 0.9 & 11.4 & 2.43 \\
$14^{* 3}$ & 69.2 & - & - & - & - \\
$15^{* 3}$ & 89.9 & - & - & - & - \\
\hline
\end{tabular}

Total amount of monomers ; $6.9 \mathrm{mmol}$, AIBN ; 2mol\%. Polymerizations were carried out at $80^{\circ} \mathrm{C}$ for 5 min.

${ }^{* 1}$ determined by ${ }^{1} \mathrm{H}-\mathrm{NMR}$ data

*2 determined by GPC calibrated with polystyrene standards

${ }^{*}$ containing toluene $(0.3 \mathrm{~mL})$ as an additional solvent 
by the protection of phenolic hydroxy group. Resulting monomer can be copolymerized with styrene and styrene derivative prepared from FA to afford a new class of bio-based plastics. On the other hand, in the case of the copolymerization with methyl methacrylate, homopolymer of second monomer was practically produced. In order to seek the applications, it is of necessity that the characteristics and reactivity of copolymers are further investigated.

\section{References}

1. U. B. Anvar, G. Mazza, Food Chem., 115, 1542 (2009).

2. K. H. Kim, R. Tsao, R. Yang, S. W. Gnu, Food Chem., 95, 466 (2006).

3. S. Mathew, T. E. Abraham, Enzyme Microb. Technol., 36, 565 (2005).

4. S. Mathew, T. E. Abraham, Crit. Rev. Microbiol., 32, 115 (2006).

5. M. L. Soto, A. Moure, H. Dominguez, J. C. Parajo, J. Food Eng., 105, 1 (2011).

6. F. Xu, R. C. Sun, J. X. Sun, C. F. Liu, B. H. He, J. S. Fan, Anal. Chim. Acta, 552, 207 (2005).

7. N. Kumar, V. Pruthi, Biotechnology Reports, 4, 86 (2014).

8. L. Mialon, A. G. Pemba, S. A. Miller, Green Chem., 12, 1704 (2010).
9. I. Barbara, A. L. Flourat, F. Allais, Eur. Polym. J., 62, 236 (2015).

10. M. Z. Oulame, F. Pion, S. Allauddin, K. V. S. N. Raju, P. -H. Ducrot, F. Allais, Eur. Polym. J., 63, 186 (2015).

11. F. Pion, P. -H. Ducrot, F. Allais, Macromol. Chem. Phys., 215, 431 (2014).

12. A. Matsumoto, T. Kubota, T. Otsu, Macromolecules, 23, 4508 (1990).

13. T. Otsu, T. Yasuhara, K. Shiraishi, S. Mori, Polym. Bull ., 12, 449 (1984).

14. A. Hosoda, H. Mori, Y. Miyake, Y. Tanaka, S. Osaki, T. Kobata, H. Taniguchi, Proceeding of 58th SPSJ Annual Meeting (3Pd140), Kobe, Japan (2009).

15. M. -A. Bazin, L. El Kihel, M. Jouanne, J. -C. Lancelot, S. Rault, Synth. Commun., 38, 3947 (2008).

16. K. Ogino, H. Sato, K. Tsuchiya, H. Suzuki, S. Moriguchi, J. Chromatogr. A, 59, 699 (1995).

17. A. Ravve, Principles of Polymer Chemistry, Plenum Press, New York (1995).

18. H. Sato, Y. Tanaka, and K. Hatada, J. Polym. Sci. Polym. Phys. Ed., 21, 1667 (1983).

19. M. S. Kharasch, M. Sage, J. Org. Chem., 14, 537 (1949).

20. T. Otsu, B. Yamada, T. Nozaki, Kogyo Kagaku Zasshi, 70, 1941 (1967). 